\title{
Mødrehelse og helsebistand
}

\author{
Betring av mødrehelsa vart i år 2000 nedfelt som eit av tusenårsmåla til FN og får stor politisk merksemd, \\ også fra norske politikarar. Framleis er svangerskap og fødsel farleg for helsa til fattige kvinner verda over. \\ Analysar av helsearbeid og bistandsøkonomi dei siste ti åra viser ein gledeleg auke i bistand, samstundes \\ som det er stor skeivfordeling mellom ulike land og mellom ulike målgrupper. Løyvingar til mødrehelse- \\ arbeid er utilstrekkelege og planar og fråsegner vert ikkje følgde.
}

\section{Hilde Engjom}

hilde.engjom@online.no

Utvalg for internasjonal helse

Den norske legeforening

Postboks 1152 Sentrum

0107 Oslo

og

Kvinneklinikken

Helse Bergen

Sidan WHO, Verdsbanken og FNs befolkningsfond (UNFPA) lanserte «Global Safe Motherhood Initiative» i 1987 har temaet vore mykje drøfta i internasjonale fora. For tusenårsmål 5 er målet å redusere mødredødelegheita med tre firedelar fra 1990 til 2015 (ramme 1).

\section{Mødredødelegheit}

«Maternal mortality ratio», mødredødsfall per 100000 levande fødde barn, vert brukt som epidemiologisk parameter. I tillegg vert tilgang til kyndig hjelp ved fødsel og tilgang til akutt fødselshjelp kartlagt. «Countdown to 2015 for Maternal, Newborn and Child Survival» analyserer dekningsgrad for tiltak og epidemiologiske data knytta til tusenårsmål 4 og 5. Per 2010 er 68 land

\section{Ramme 1}

\section{FNs tusenårsmål}

1. Avskaffe ekstrem fattigdom og hungersnaud

2. Grunnskuleutdanning for alle

3. Fremme likeverd mellom kjønna og betre kvinner si stilling

4. Redusere barnedødelegheit

5. Betre mødrehelsa

6. Kjempe mot hiv, malaria og andre sjukdommar

7. Sikre eit bærekraftig miljø

8. Utvikle eit globalt partnerskap for utvikling registrerte, og desse står for $95 \%$ av alle barne- og mødredødsfall (1). Nokre land held fram med å gjere framgang innafor mødre-, nyfødd- og barnehelse, nokre har fått forverra situasjonen sin. Dei fleste har ein uendra situasjon eller for langsam endring til å kunne nå tusenårsmåla innan 2015. Dekninga er betre for programbaserte intervensjonar som vaksinasjon og vitamin A-tilskot, enn for tenesteavhengige tiltak som kyndig fødselshjelp og bruk av behandlingsalgoritmer for sjuke barn. I nokre land får no ca. $50 \%$ av hivpositive kvinner tilgang til medikamentbehandling for å redusere risikoen for smitte til barnet ved fødselen. I halvparten av dei registrerte landa er det framleis stor fattigdom, låg prosentdel med grunnskuleutdanning og meir utbreidd underernæring i folkesetnaden. Dette samvarierer med høg barne- og mødredødelegheit (1).

\section{Framgang?}

Nyleg publiserte analysar for mødredødelegheit viser ein global reduksjon i mødredødsfall fra 536000 i 1980 til 350000 per år i 2008 (2). Berekningane er baserte på tilgjengelege data, men datagrunnlaget er framleis mangelfullt i mange låginntektsland. Reduksjonen er framleis for låg til å nå tusenårsmål 5 , men syner meir framgang enn tidlegare. Latin-Amerika og AustAsia, mellom anna, viser synkande trend som samvarierer med fall i fertilitetsraten, betra hushaldsinntekt, betra utdanning for jenter og mogleg betring i fødselsomsorgen. I Afrika sør for Sahara er situasjonen urovekkande. Fattigdom saman med infeksjonssjukdommar som hiv og tuberkulose er medverkande årsaker. Ni land står no for nærare $80 \%$ av mødredødsfalla (2).

\section{Tiltak}

$60 \%$ av verdas kvinner føder framleis heime, i nokre område er denne prosentdelen endå høgare (3). Førebygging av svangerskapsrelaterte komplikasjonar kan grupperast på tre nivå: unngå svangerskap, førebygge komplikasjonar, og hindre død når komplikasjonar oppstår. Familieplanlegging og tilgang til trygge metodar for svangerskapsavbrot er eit ømtoleg tema i mange land. Dette påverkar første leddet i kjeda. Omsorg og oppfølging gjennom svangerskapet har tidlegare hatt ei meir sentral rolle i planlegging av grunnleggande svangerskapsomsorg (essential obstetric care) (3). Dødsfall knytta til svangerskap skjer hovudsakeleg i siste trimester, ved fødselen og vekene etter. Difor har fødselsomsorg og behandling når det oppstår ein komplikasjon (emergency obstetric care), vore sentrale i mødrehelsearbeidet dei siste ti åra $(3,4)$. Ettersom anemi, dårleg ernæringstilstand og infeksjonssjukdommar som tuberkulose, malaria og hiv aukar faren for både mor og barn, er også generell svangerskapsomsorg viktig i land med høge dødelegheitstal $(2,5,6)$. Ei rekke ulike tiltak har vore forsøkte for å betre tilhøva for mor og nyfødde barn. Ulike døme på dette er utlevering eller sal av fødesett, fødselsplanlegging og ulike program med tiltak knytta til einskildfaktorar som blødning. Nytteverdien kan framstå klar intuitivt, men har i liten grad blitt dokumentert $(7,8)$. Mangelen på helsepersonell er størst i område der mødre- og nyføddødelegheit er størst. Eit anna tiltak har difor vore opplæring av lekpersonar og tradisjonelle fødselshjelparar utan at ein til no har kunne påvise sikker effekt av dette (9).

\section{Standardisering av fødselshjelp}

"Averting Maternal Death and Disability» vart utvikla ved Colombia-universitet og vert no teke i bruk i fleire land. Den internasjonale gynekologforeininga, FIGO, deltek i dette arbeidet i samarbeid med WHO (10). Her arbeider ein for å prøve å standardisere omgrepet kyndig fødselshjelp og å standardisere innhaldet $\mathrm{i}$ akutt fødselshjelp. Helsesenter som tilbyr grunnleggande akutt fødselshjelp skal etter planen kunne behandle infeksjon og blødning med intravenøse medikament, ein skal kunne hente ut placenta og placentarestar samt tilby vaginal assistanse (vakuum/tang) ved forløysning. 


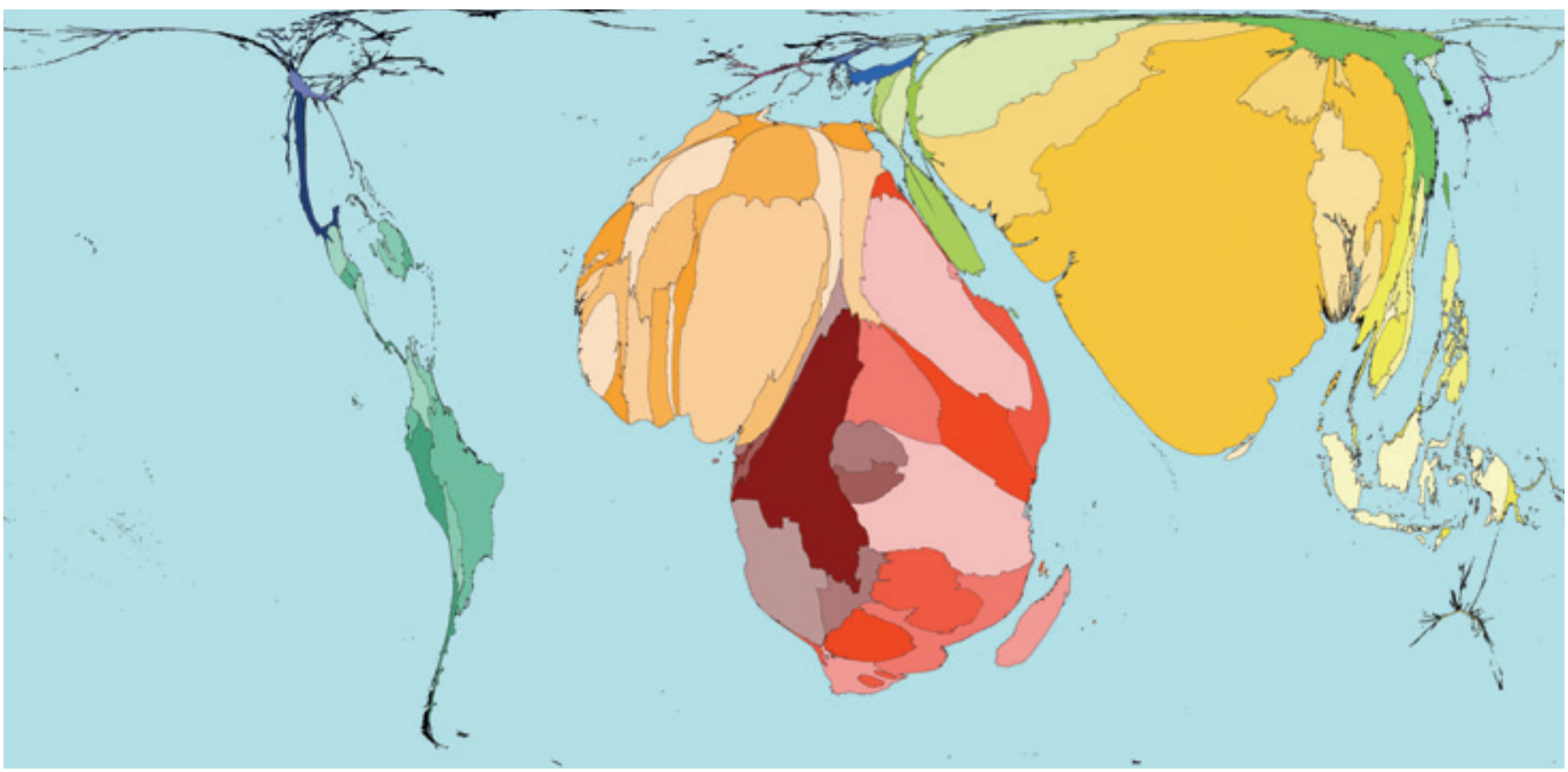

Figur 1 Mødredødsfall framstilt kartografisk ved å dele verdskartet inn i 12 regionar. Spektralfargar med djupraudt for lågast inntekt per innbyggar, fiolett høgast. Storleiken på landa framstiller delen av verdas mødredødsfall. Basert på tall fra 2000. @ Copyright SASI Group (University of Sheffield) and Mark Newman (University of Michigan).

Avansert fødselshjelp omfattar i tillegg keisersnittberedskap og høve til å gi blodoverføring. Ein tilrår minimum fem senter per 500000 innbyggarar, eitt av desse bør vere avansert. Av omsyn til kvinner i distrikta vert òg reiseavstand framheva, men her er det ikkje definert noko grense i reisetid (11).

Analysar av tilgang til akutt fødselshjelp har vist at det dei fleste stader finst tilgjengelege bygningar som ved utbetring kan tilby tenestene nær bustaden til kvinna (3). Vanlege behov for utbetring inkluderer renovasjon og reparasjon av utstyr, betra forsyningslogistikk og opplæring av helsepersonell i aktuelle prosedyrar, saman med oppfølging i form av supervisjon og leiarsystem. Ved tilsyn har ein likevel oppdaga at mange senter ikkje kan tilby alle delar av grunnleggande eller avansert fødselshjelp. Ein fann òg at mange fødesenter retta mot handtering av vanlege fødslar og friske nyfødde, ikkje kunne handtere komplikasjonar. Det vert framheva at behovet for kunnskap og trening i å handtere komplikasjonar også er ein tankevekkar når det gjeld definisjonen av kyndig fødselshjelp og kven som kan yte dette. Ein tilrår inspeksjon for å fastslå om helsetenesta kan yte rett behandling, og WHO har laga ei handbok til bruk i dette arbeidet $(3,11)$.

\section{Oppbygging og finansiering av helsebistand}

Arbeidet med FNs tusenårsmål for helse førte til oppretting av ei rekke globale helseinitiativ. Desse representerer samla arbeid på tvers av landegrenser retta mot tilstandar som i hovudsak rammar fattige land og som representerer ei stor byrde for helsetenesta i desse landa (12). Ein har gått inn for målretta, kostnadseffektive helseintervensjonar og teknologiutviklig knytta til spesifikke sjukdommar. Privat sektor, filantropiske fond og det sivile samfunn er drege inn i helsetenesteutviklinga. Det finst ei rekke ulike initiativ, men fire store dominerer økonomisk og politisk (12) (ramme 2).

\section{Donorstyrt prioritering}

Kvart initiativ er retta mot ein eller eit fåtal sjukdommar. Startfasen vart prega av rask politisk handling og det fanst korkje midlar eller metodar for forskingsbasert evaluering og vurdering av resultat. Internasjonale fagmiljø har kritisert manglande oppbygging av nasjonal kompetanse innan helseplanlegging og prioritering, lite forskning og utdanning $(12,13)$. Donorstyrt prioritering for bruk av midla gir mindre rom for styring og prioritering i einskildlandet. Helseinitiativa har òg rekruttert fagfolk frå den offentlege helsetenesta og dels etablert eigne forsyningskjeder og rapporteringslinjer framfor å betre det nasjonale systemet (12). Problemet er vedgått, og OECD-landa har gjennom Paris-fråsegna nedfelt prinsippet om styrking av landa sin evne til å ivareta eigne behov (14). I praksis har økonomiske verkemiddel som sektorbasert støtte, direktebidrag til statsbudsjett eller gjeldslette sjeldan vore brukte (13, $15,16)$. Norge prøver modellen for sektorbasert bistand i Tanzania (17).

\section{Fordeling}

Trass i auka løyvingar til helseutvikling er rekneskapen uoversiktleg. OECD-landa sin Official Development Assistance-database er mest brukt. Denne inkluderer ikkje bistand frå land utanfor OECD, til dømes land i Midtausten eller Kina, og heller ikkje løyvingar frå filantropiske fond som Bill and Melinda Gates Foundation $(13,15,16)$.

Alle berekningar viser ein stor auke i bistand gjennom 2000-06/07 og bistand til helsearbeid utgjer ein aukande del $(15,16)$. For 2006 vart det registrert løyvingar for 13,3 mrd. amerikanske dollar (15). Auken $i$ helsebistand er særskilt knytta til hiv/aids. Det er få store prosjekt med budsjett over 10 mill. dollar, men desse representerer to

\section{Ramme 2}

\section{Dei største globale helseinitiativa}

Global Fund to fight AIDS, Tuberculosis and Malaria; «Global Fund; GF». Forvaltar pengar fra givarland, fordelte 2,6 mrd. amerikanske dollar i 2007

- Global Alliance for Vaccines and Immunisation; GAVI

Forvaltar pengar fra givarland og filantropiske fond som Bill and Melinda Gates Foundation. Delte ut 889 mill. amerikanske dollar i 2007

- US Presidents Emergency Plan for AIDS Relief; PEPFAR

Delte ut 5,4 mrd amerikanske dollar i 2007

- Verdsbanken: fleire program, det største er «Multi Country AIDS Program; MAP»

Forvaltar pengar fra giverland, totale løyvingar til helse 1,6 mrd. amerikanske dollar i 2008 
tredelar av pengesummen for perioden 2002-06. Meir enn halvparten av desse store prosjekta rettar seg mot hiv/aids, malaria, tuberkulose og andre smittsame sjukdommar, kun $9 \%$ er retta mot reproduktiv helse (15). Dei 20 minst utvikla landa tek imot ein tredel av helsebistanden. Det er store geografiske variasjonar mellom landa. Ti land representerer ein femdel av samla folkesetnad og tek mot halvparten av bistanden. Kun for 7 land representerer løyvingar til mødrehelsearbeid meir enn $10 \%$ av bistanden. Hiv/aids retta bistand dominerer, men følgjer ikkje sjukdomsforekomst (15). Land med låg forekomst av hiv/aids men med høg sjukdomsbyrde og dødelegheit av andre årsaker, får mindre bistand $(15,16)$.

\section{Fragmentering}

To tredeler av alle registrerte løyvingar går til prosjekt med budsjett under 0,5 millionar amerikanske dollar. Dette representerer mindre enn $3 \%$ av helsebistanden (15). Prosjektplanlegging, søknad og rapportering er arbeidskrevjande både for givar og mottakar. Tala synleggjer dermed fragmentering av bistand innan helsefeltet. Ein kan tenke seg at små prosjekt sikrar lokal forankring og eigarskap i lokalsamfunnet, medan det er mindre rom for planlegging og prioritering for nasjonale styresmakter, og at det i liten grad vert sett av ressursar til leiing, logistikk og utdanning utover det reint prosjektretta $(12,13,15)$.

\section{Oppbygging av helsetenester}

Helsetenester i samband med svangerskap og fødsel er ein av grunnsteinane i helsetenesta. I Norge var jordmorutdanning og utbygging av fødeinstitusjonar sentrale tiltak for tryggare fødselsomsorg. Andre faktorar som utdanning, fattigdom og likeverd er sterkt knytta til reproduktiv helse (6).

Land med mange barne- og mødredødsfall har i liten grad etablert gode registerordningar slik at ein kan få sikker epidemiologisk informasjon. Det er ei krevande oppgave som høyrer saman med overordna politisk prioritering, organisering av helsetenesta generelt, utdanning og opplæring av helsepersonell. Dermed er det tankevekkande at ein svært liten del av bistandsressursane vert knytta til å styrke helsesystemet generelt og særskilt tenester knytta til reproduktiv helse. Utbygging av helsesektoren er langsiktig og gir ingen rask utveg for tenesteyting eller samfunnsmedisinsk effekt. Forskningsbasert evaluering av innhald og arbeidsform innan mødrehelsetiltak og helsebistand er lenge blitt etterlyst og er ein svært viktig del av heilskapen $(7,18)$.

\section{Oppsummering}

Mødrehelsearbeid har vorte vektlagt i fleire tiår, men er samstundes fanga i grenseland mellom horisontale og vertikale program og i krav om kostnadseffektive intervensjonar med raske resultat.
Politikarar har verda over vist ei viktig haldningsendring og vilje til å satse på helsetenester. I låginntektsland vert dette finansiert gjennom nasjonale løyvingar og bistand. Samverknaden mellom bistand og nasjonale løyvingar er utilstrekkeleg kartlagt. Både nasjonalt og internasjonalt må ein difor sjå nytten av å prioritere oppbygging av helsetenester for kvinner og barn og gjere slike prioriteringar moglege for helsestyresmakta i dei ulike landa (19). Dei nye finansieringsmodellane for bistand, som til dømes «Global Fund to fight AIDS, Tuberculosis and Malaria», har vist at det er mogleg å mobilisere løyvingar til helsearbeid. Mange tek nok til orde for å utvide mandatet til Global Fund til å omfatte alle tusenårsmåla for helse, slik at og mor-barnarbeidet kan få tilgang til desse midla.

Men politikk krev òg at ein raskt kan framvise resultat for å grunngje løyvingar og prioriteringar. Då er bilete av friske barn eller eit einskildsjukehus betre illustrasjonar enn omgrep som generell budsjettstøtte og oppbygging av forsyningstenester og utdanningsinstitusjonar. Legeforeningen har gjennom policynotat om migrasjon og utdanningssamarbeid vist til helsearbeidarar si nøkkelrolle i helsetenesta og peika på nytteverdien av auka samarbeid om utdanning og forsking (20). Korleis kan vi som fagpersonar og velferdssamfunn sikre fattige kvinner trygge kår og del i helse som eit felles gode? Dette vert eit viktig ordskifte for framtida som eg håper de vil delta $i$.

Oppgitte interessekonflikter: Ingen

\section{Litteratur}

1. Countdown to 2015 decade report (2000-2010): taking stock of maternal, newborn and child survival. Genève: WHO, UNICEF, 2010 www.countdown2015mnch.org/ reports-publications/2010-report (28.5.2010)

2. Hogan MC, Foreman KJ, Naghavi M et al. Maternal mortality for 181 countries, 1980-2008: a systematic analysis of progress towards Millennium Development Goal 5. Lancet 2010; 375: 1609-23.

3. Paxton A, Bailey P, Lobis S et al. Global patterns in availability of emergency obstretic care. Int J Gynecol Obstet 2006; 93: $300-7$

4. Ronsmans C, Graham W; Lancet Maternal Survival Series steering group.. Maternal mortality; who, when, where and why. Lancet 2006; 368: 1189-2000.

5. Filippi V, Ronsmans C, Campbell OM et al. Maternal health in poor contries: the broader context and a call for action. Lancet 2006: 368. 1535-41.

6. Sundby J. Tusenårsmål 5 - reduksjon av mødredødelighet. Tidsskr Nor Legeforen 2009; 129: 2394-6.

7. Maine D. Detours and shortcuts on the road to maternal mortality reduction. Lancet 2007; 37 $1380-2$.

8. Burchett HE, Mayhew SH. Maternal mortality in low-income countries: what interventions have been evaluated and how should the evidence base be developed further? Int J Gynecol Obstet 2009; 105: 78-81.

9. Lewin S, Munabi-Babigumira S, Glenton C et al. Lay health workers in primary and community health care for maternal and child health and the management of infectious diseases. Cochrane Database Syst Rev 2010, nr. 3: CD004015.

10. Benagiano G, Thomas B. Saving mothers lives: the FIGO Save the Mothers initiative. Int J Gynecol Obstet 2003; 80: 198-203.
11. WHO UNFPA UNICEF AMDD Monitoring emergency obstetric care - a handbook. Genève: WHO, 2009. whqlibdoc.who.int/publications/2009/ 9789241547734 eng.pdf (31.8.2010).

12. Samb B, Evans T et al; World Health Organization Maximizing Positive Synergies Collaborative Group. An assessment of interactions between global health initiatives and country health systems. Lancet 2009: 373: 2137-67.

13. Global aid architecture and the health millennium development goals. Study report 1/2009. Oslo: Norad, 2009. www.norad.no/en/Toolstand+ publications/Publications/Publication+ Page?key=146674 (31.8.2010)

14. OECD. The Paris declaration. www.oecd.org/ document/18/0,3343,en_2649_3236398_35401554 1 1 1 1,00.html (31.8.2010).

15. Piva P. Dodd R. Where did all the aid go? An in-depth analysis of increased health aid flows over the past 10 years. Bull World Health Org 2009: 87: $930-9$

16. Ravishankar N, Gubbins P, Cooley RJ et al. Financing of global health: tracking development assistance for health from 1990 to 2007. Lancet 2009: 373; $2113-24$

17. Austveg B. Norsk støtte til helsesektoren i Tanzania. Tidsskr Nor Legeforen 2009; 129: 2397-400.

18. Sanders D, Haines A. Implementation research is needed to achieve international health goals. PLoS Med 2006; 3: e186.

19. Lu C, Schneider MT, Gubbins P et al. Public financing of health in developing countries: a crossnational systematic analysis. Lancet 2010; 375: $1375-87$

20. Legeforeningen, policynotat $1 / 2010$. Styrket samarbeid om utdanning av leger i lav- og mellominntektsland. www.legeforeningen.no/id/164824.0 (28.5.2010)

Manuskriptet ble mottatt 3.6. 2010 og godkjent 13.9. 2010. Medisinsk redaktør Siri Lunde. 